\title{
Patient's safety culture among health care professionals in Tunisian Center-Est University Hospital
}

\author{
N Bouafia*, M Mahjoub, R Hellali, W Bannour, A Bencheikh, O Ezzi, A Asma, Z Nawel, N Mansor \\ From 3rd International Conference on Prevention and Infection Control (ICPIC 2015) \\ Geneva, Switzerland. 16-19 June 2015
}

\section{Introduction}

Nowadays, patients' security arouses more and more decision-makers and health workers. Development of safety culture is fundamental pillar to any strategy for improving quality and safety care. Thus, we conducted our work in order to measure level of patients' safety culture among healthcare professionals, in our hospital.

\section{Objectives}

Measure level of patients' safety culture among healthcare professionals in order to improve strategies of healthcare quality and safety in our hospital.

\section{Methods}

We conducted, in 2013, a descriptive study among all licensed physicians $(n=116)$ and a representative sample of paramedical staff $(n=203)$ exercising at university hospital center Farhat Hached Sousse (Tunisia). Measuring instrument used is a valid questionnaire containing ten safety care dimensions.

\section{Results}

Participation rate was $90.5 \%$.

$44.9 \%$ of respondents felt that security level of their services is low. Overall score of different dimensions varies between $32.7 \%$ and $68.8 \%$. Dimension having most developed score (68.8\%) was perception of "Frequency and reporting adverse events". Dimension with lowest score (32.7\%) was "Management support for safety care".

Hospital Hygiene, University Hospital Farhat Hached Sousse Tunisia, Jawhara, Tunisia 